Article

\title{
Utilization of ICT as a Digital Infrastructure Concerning Disaster Countermeasures in Japan
}

\author{
Kayoko Yamamoto \\ Graduate School of Informatics and Engineering, University of Electro-Communications, Chofu-shi, \\ Tokyo 182-8585, Japan; kayoko.yamamoto@uec.ac.jp; Tel.: +81-42-443-5728
}

Received: 10 August 2020; Accepted: 5 September 2020; Published: 10 September 2020

check for updates

\begin{abstract}
The present study aimed to describe the utilization of Information and Communication Technology (ICT) as a digital infrastructure concerning disaster countermeasures in Japan. Specifically, the study introduced development cases of the systems integrating social media and Geographic Information Systems (GIS), and presented the utilization potential as a digital infrastructure. Additionally, taking up Twitter as a familiar digital infrastructure, the study also presented its utilization potential based on the case of the heavy-rain disaster in Western Japan in 2018. As a result, due to the close relationship between the reality and virtual spaces, the issue is how to make the information circulating in the virtual space efficiently and effectively aid in the rescue and support activities in the reality space. The above systems are effective in order to solve such an issue, because these can efficiently consolidate the essential information on the digital map of Web-GIS. Additionally, it is necessary to set rules for the utilization of social media, and sift through information and share only the necessary information to the affected local governments and those involved in the rescue and support activities. Furthermore, various information communication methods including verbal calls in addition to ICT are necessary especially for people who are vulnerable to information.
\end{abstract}

Keywords: information and communication technology (ICT); digital infrastructure; geographic information systems (GIS); social media; disaster countermeasures

\section{Introduction}

In recent years, countermeasures for natural disasters have become a high priority all around the world due to the global increase in weather disasters such as typhoons and local torrential rainfall, as well as volcanic eruption, drought, heat waves and earthquakes. According to the White Paper on Disaster Management 2018 [1], among disaster countermeasures such as "self-help", "mutual help" and "public help", the most fundamental method is "self-help" which is a countermeasure individually conducted. It is important for each individual to have a high disaster prevention awareness in everyday life in order to minimize the damage through countermeasures, as rescue teams are not able to immediately reach all disaster victims during a disaster. Therefore, it is important to enhance the government's "ability to inform" and the public's "ability to become aware" by widely and appropriately providing disaster information, accurately grasping hazardous areas as well as evacuation centers in case of a disaster before it occurs, and accumulating disaster information with location information (Yamamoto, 2016) [2]. In order for this to lead to "mutual help" and "public help", sufficient accumulation and sharing of disaster information within the local community including residents, corporations and the local government are essential during normal times.

On the other hand, in recent years in Japan, a cloud computing society where the internet can be reached from various information tools has been established, and Japan has entered the age of Internet of Things (IoT) and Internet of Everything (IoE) in which various things can be connected to the internet. Based on such current conditions, the realization of a "super-smart society" was clearly 
set up ahead of other countries as the first pillar in the 5th Science and Technology Basic Plan (Cabinet decision, January 2016) [3], and a series of initiatives towards this realization is called the "Society 5.0". The society mentioned above is able to efficiently gather and accumulate disaster information as local knowledge made up of knowledge from the experience and everyday life of residents as well as the expertise based on scientific findings through the effective use of Information and Communication Technology (ICT) (Science Council of Japan, 2008; Yanagisawa et al., 2012; Okuma et al., 2013) [4-6].

Based on the background above, the present author and her co-researchers worked together with local communities during normal times to develop a disaster information system as a countermeasure for damage reduction in disasters by integrating social media and Web-GIS in order to promote the utilization of disaster information as local knowledge (Yamamoto et al., 2015) [7]. Additionally, multiple information systems were integrated to develop a spatiotemporal information system. With the function of social media mapping, which is one of the most important functions, the submitted data on social media with location information were consolidated on a digital map of Web-GIS, indicating the utilization potential of using such information during disasters (Makino et al., 2018; 2019) [8,9].

Considering these circumstances, the present study aims to describe the utilization of ICT as a digital infrastructure concerning disaster countermeasures in Japan. Specifically, the present study will present the utilization potential of the above two types of systems which were developed integrating social media and GIS. Additionally, taking up Twitter as a familiar digital infrastructure, the present study will also present its utilization potential based on the case of the heavy-rain disaster in Western Japan in 2018 (from June to July in 2018). For this, Section 2 will introduce the results of preceding studies in the related academic fields, and demonstrate the novelty of the preset study. Section 3 will review the changes in the information communication environment in Japan from the 1990s onwards. Section 4 will introduce various information communication methods for disasters in Japan, and mention the significance of ICT as a digital infrastructure concerning disaster countermeasures. Sections 5 and 6 will respectively introduce two types of system development cases, and indicate the utilization potential of ICT as a digital infrastructure concerning disaster countermeasures. Section 7 will consider the cases of social media utilization during the heavy-rain disaster in Western Japan in 2018, and indicate the utilization potential of Twitter as a familiar digital infrastructure for disaster countermeasures. Lastly, Section 8 will summarize the conclusion of the present study and mention future research projects.

\section{Related Work}

The preceding studies on ICT as a digital infrastructure concerning disaster countermeasures are divided into three study fields, namely: (1) studies on the development of a new digital infrastructure; (2) studies on the utilization of an existing digital infrastructure; (3) studies on the proposal of a new digital infrastructure in the future. The following will introduce the major preceding studies in the above three academic areas, and demonstrate the novelty of the present study in comparison with the others.

In (1) studies on the development of a new digital infrastructure, Molina et al. (2011) [10] developed a pioneer system (Andean Information System for Disaster Prevention and Relief: SIAPAD) for sharing spatial information for the Andean Community (Bolivia, Colombia, Ecuador and Peru). Wan et al. (2014) [11] developed a public cloud-based flood cyber-infrastructure (CyberFlood) that collects, organizes, visualizes and manages several global flood databases for authorities and the public in real-time. Ogata et al. (2016) [12] developed a Twitter-based safety confirmation system which is available when other digital infrastructure is disrupted. Bhattacharjee et al. (2019) [13] developed a post-disaster map builder which is a crowdsenced digital pedestrian map construction system over smartphone based Delay Tolerant Networking (DTN), using battery powered mobile handheld devices in the disaster affected areas. Cao et al. (2019) [14] developed a rapid assessment system for seismic intensity area using the data related to mobile base stations in China. 
In (2) studies on the utilization of an existing digital infrastructure, targeting the affected areas of the great East Japan earthquake, Inomo et al. (2012) [15] verified the usefulness of disaster prevention administration radio system, Harada et al. (2012) [16] reported the effective use of a cognitive wireless router in a chaotic state of digital infrastructure, and Hamaguchi et al. (2014) [17] proposed and demonstrated the utilization potential of a wireless telecommunication system. Targeting the use of Twitter at the time of the great East japan earthquake, Yoshimura et al. (2012) [18] investigated the logs of 34 governmental accounts and summarized the operating guideline for governments, and Enomoto et al. (2013) [19] proposed a method to extract false rumors from tweets. Additionally, Yamada et al. (2019) [20] grasped the characteristics of tweets submitted at the times of past large-scale natural disasters in Japan. Nakano et al. (2019) [21] proposed the role of digital infrastructure based on the survey on the heavy-rain disaster in Western Japan in 2018.

In (3) studies on the proposal of a new digital infrastructure, Alazawi et al. (2014) [22] proposed emergency response systems for disasters of various scales with a focus on transportation systems for future cities in Philippine. Freeman (2017) [23] showed the need to develop alternative infrastructure to assist Disaster Risk Reduction and Recovery construction (DRRR) as an energy and communication infrastructure for disaster resilience in rural and regional Australia. Fan et al. (2019) [24] presented a paradigm of a disaster city digital twin, which will be developed integrating artificial and human intelligence for disaster management.

The present study is located in (2) studies on the utilization of an existing digital infrastructure, and there is a rich accumulation of preceding studies in this academic area. Comparing the preceding studies mentioned above, the present study demonstrates the novelty, verifying the utilization potential of ICT as an existing digital infrastructure concerning disaster countermeasures in Japan. Additionally, in this academic area, Yoshimura et al. (2012) [18], Enomoto et al. (2013) [19] and Yamada et al. (2019) [20] just targeted twitter among social media. However, as explained in the latter sections, the present study takes up social media and GIS of ICT as a digital infrastructure, and indicates their utilization potential in disaster countermeasures, considering the characteristics of information communication environment and methods, and referring to the results of survey on the utilization of ICT at the times of past large-scale natural disasters in Japan.

\section{Change in the Information Communication Environment in Japan from the 1990s Onward}

\subsection{Development of the Advanced Information Communication Network Society}

In Japan, the Basic Act on the Formation of an Advanced Information and Telecommunications Network Society (Basic Act on IT) became effective in 2000, and the advanced informatization was initiated (Ministry of Internal Affairs and Communications, 2002) [25]. Additionally, Japanese society was transformed from a ubiquitous society to a cloud computing society which was conducted by means of a sequence of advanced information strategies from the year 2000 onwards including "e-Japan" in 2000, "u-Japan" in 2006 and "i-Japan 2015" in 2010. These advanced information strategies respectively aimed at the realization of the world's most advanced information technology (IT) nation, ubiquitous network society, and digital society for security and vitality. Therefore, anyone in an internet-accessible environment as well as anyone with an information terminal can access the internet regardless of the time or place, realizing a society where information systems can be easily utilized.

Further, as mentioned in the previous section, in recent years, Japan has come to an age of IoT and IoE where various things can be connected to the internet. As a result, Japan specifically set up the "Development of future industry and social transformation (realizing a world-leading 'super-smart society')" as a first pillar in the latest 5th Science and Technology Basic Plan (Cabinet decision, January 2016) [3]. This new society is positioned after the "hunter-gatherer society", the "agrarian society", the "industrial society" and the "information society", and a series of initiatives towards the realization of this society is called "Society 5.0". In Part 1 of the White Paper on Science and Technology 2016 published based on the 5th Science and Technology Basic Plan [26], the "super-smart society" is 
straightforwardly defined as a society that is "achieved by integrating the reality and virtual spaces through the advancement of networks, and the development of technology for big data analysis and Artificial Intelligence (AI)". The technology needed to realize this new society is mostly related to the information field. Therefore, a digital infrastructure is an important fundamental infrastructure that supports various other infrastructures, and its importance will increasingly grow in the new society.

\subsection{Changes in the Information Communication Environment from the 1990s Onward}

Figure 1 shows the penetration rate of the PC, internet and mobile information terminal over the last 20 years (1993-2012). The great Hanshin-Awaji earthquake was in 1995, the Mid Niigata Prefecture Earthquake in 2004 and the great East Japan earthquake in 2011. As shown in Figure 1, the progress of the advanced information communication network is significant since the great Hanshin-Awaji earthquake up until the present day, and has greatly changed the information communication environment surrounding the general public. At the time of the great Hanshin-Awaji earthquake, the internet was used from PCs and mobile information terminals were also becoming increasingly common. In contrast, the information communication environment today is more complex and anyone can easily spread information, as the internet can be accessed from mobile information terminals such as smartphones and tablets in addition to PCs.

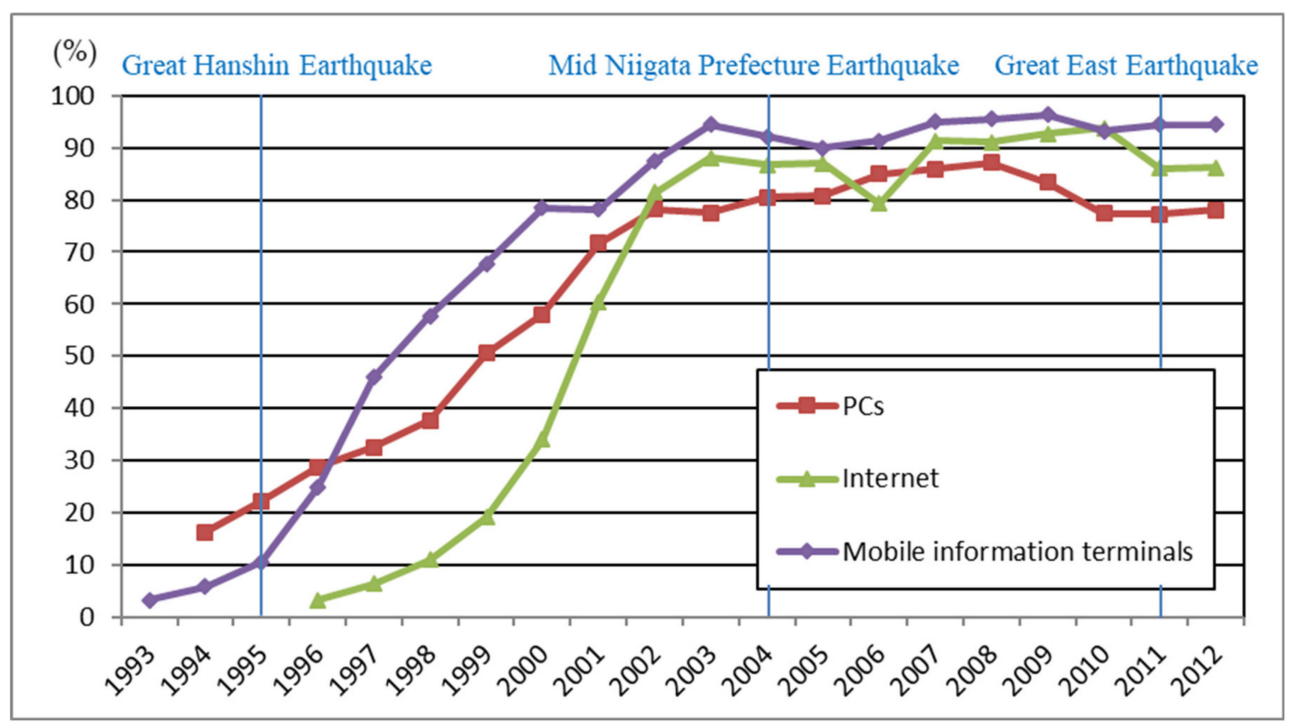

Figure 1. Penetration rate of the PCs, internet, and mobile phones (1993-2012). Note-created based on the Consumer Behavior Forecasting Survey 2014 [27].

According to the data for recent years, which is obtained from the White Paper on Information and Communications 2016 [28], due to the restrictions on obtaining data, the penetration rate in 2015 was $95.8 \%$ for mobile phones and PHS, $72.0 \%$ for smartphones, $76.8 \%$ for PCs and $33.3 \%$ for tablets. The rapid spread of mobile information terminals such as smartphones and tablets in recent years has diversified communication methods, and enabled individuals to easily send and receive interactive information right then and there as well as search for information.

\section{The Significance of ICT as a Digital Infrastructure Concerning Disaster Countermeasures}

\subsection{The Various Information Communication Methods Used during Disasters}

According to Yamamoto (2017) [29], various initiatives have been taken to minimize information vacuums as the great East Japan earthquake (2011) caused immense damage to a digital infrastructure, and a broad area was left blank in terms of information communication immediately after the earthquake. Due to the widespread and immense damage caused, a new type of media such as social media, 
where individuals can send detailed information without the limitations of mass media, was utilized. In particular, individuals on social media can send information from both PCs and mobile information terminals enabling the damage situation to be widely communicated before mass media can enter the damaged area. This is made possible by the spread of various social media in which individuals can send and receive information in multiple forms by combining images, videos, voice recordings in addition to texts. In this way, social media has become part of the disaster information sharing system (L-Alert), and has fulfilled a big role in the diversification and layering of information communication methods. However, various issues have emerged regarding the utilization of the internet during disasters such as the massive amount of communication traffic, communication blackouts, as well as measures to deal with false information and chain emails. This is one of the biggest differences to when the great Hanshin-Awaji earthquake (1995) occurred.

At the time of the great Hanshin-Awaji earthquake, telephones and transportation were disrupted in the damaged area as well as its surrounding areas creating a donut-shaped information vacuum in the center of the damaged area. Additionally, information was one-sidedly provided through mass media such as newspapers, magazines, radio and television. Furthermore, the information reported immediately after the earthquake was mainly provided through radio and television, while the internet was mainly used after the rescue and relief stage. However, the usefulness of GIS has come to be positively recognized after the great Hanshin-Awaji earthquake. Specifically, the database compilation of the damage situation was created using GIS, and this was used to support restoration plans in the affected areas.

In the heavy-rain disaster in Western Japan in 2018, various disaster information was provided by national institutions and private corporations related to surveys and GIS using digital maps, and satellite images and aerial photos. Additionally, various entities cooperated in consolidating activities concerning disaster countermeasures using ICT including Web-GIS. Because ICT was effectively used in such disaster countermeasures, a wide variety of information was transmitted and updated in real-time, and the voluntary provision of information by various entities or industry-academia-government collaborations increased. Furthermore, these various disaster countermeasures were widely made known through both mass media and social media.

\subsection{The Significance of ICT as a Digital Infrastructure}

The preconditions for using ICT as a digital infrastructure for disaster countermeasures is that the information communication environment (internet connection, electricity, and the use of information terminal) must be well-maintained all throughout Japan. The probability of issues concerning the information communication environment during disasters being solved in the near future is high, as technological development in the related fields are making rapid advances such as the establishment of mobile internet bases mounted on cars or balloons during disasters, the establishment of additional internet base stations during normal times, the supply of electricity using hybrid cars, and the implementation of battery saving mode in emergencies as well as battery extension of mobile information terminals. Additionally, the utilization of satellite communication networks can now be used in case the overland information network cannot be used immediately after a disaster.

The Committee for Policy Planning on Disaster Management Final Report of the Central Disaster Management Council (2012) [30] indicated the need to gather information from private media including social media, as the government has its limitations in gathering information. Similarly, as the utilization of geographical space information (G space information) can be extremely effective in the coherence in situational awareness and decision-making support, the necessity of progressing maintenance and sharing of static information during normal times as well as development of a system to promptly gather dynamic information were also indicated. Additionally, the development of GIS is considered to be promoted in order to support disaster countermeasures in the Master Plan for Disaster Prevention (2016) [31] as well. Therefore, social media, which has been deeply rooted into our daily life and can rapidly spread information, and GIS, which enables the consolidation and sharing of information 
using digital maps, have become an important foundation of all general infrastructures as a digital infrastructure in modern-day Japan and are considered to fulfill a vital role in disaster countermeasures. In recent years, GIS has especially been useful in the work of information volunteer and GIS volunteer where disaster countermeasures are conducted using GIS.

\section{Utilization Potential of Social Media GIS for Disaster Information System as a Digital Infrastructure}

Yamamoto et al. (2015) [32] considered the changes in ICT as well as the role of a digital infrastructure in disaster countermeasures as mentioned in the previous sections, and indicated that it is possible for GIS to have an interactive communication function to be used between users as shown in Figure 2. It further proposed this new GIS called "social media GIS", differentiating it from the conventional Web-GIS. It developed the social media GIS which incorporated the accumulating and displaying functions of submitted information according to the location information and content with the system combining $3 \mathrm{Web}$ applications including social media (social networking service (SNS) and Twitter) and Web-GIS, and utilized it in the operation in Mitaka City, Tokyo Metropolis, as a disaster information system for both disasters and normal times. The system design took the local characteristics of Mitaka City into consideration, and reflected the requests of various entities in the local community mainly for earthquakes.

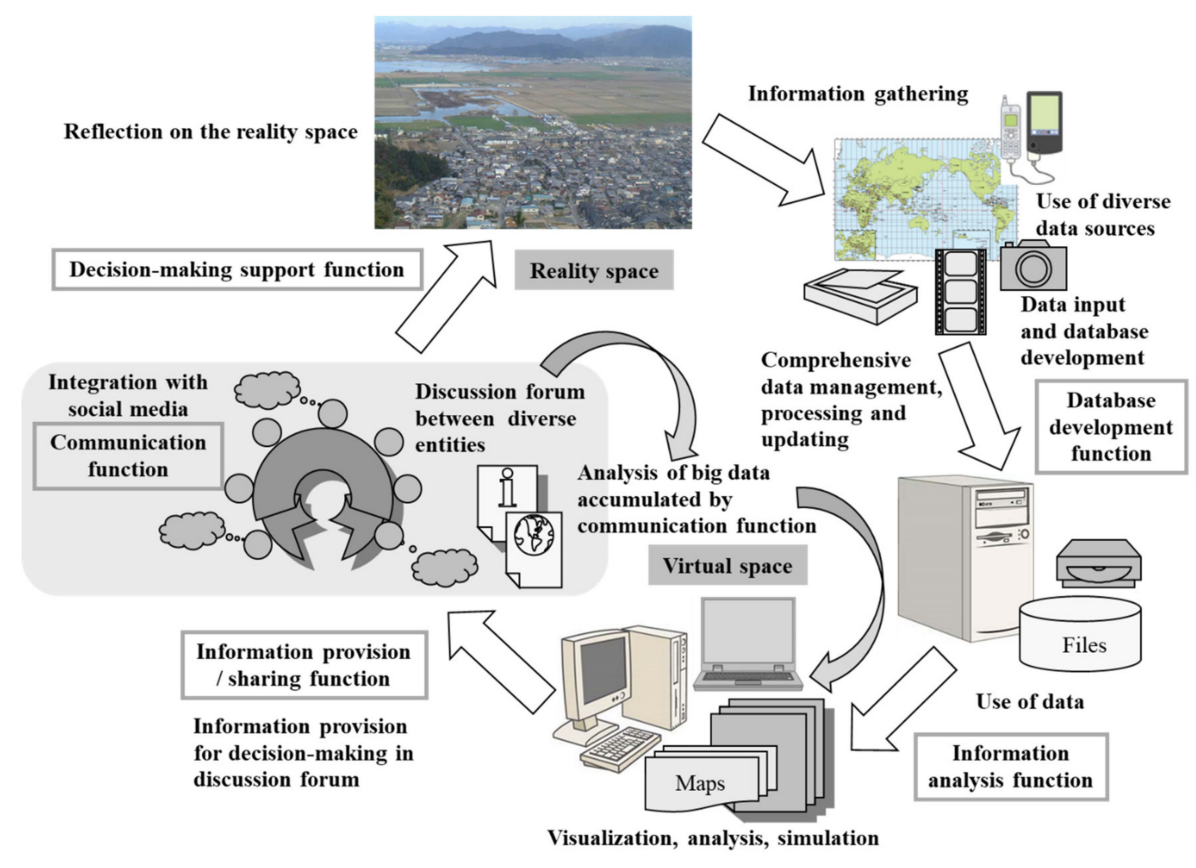

Figure 2. The various functions of Geographic Information Systems (GIS) and their involvement in society.

The system has 3 kinds of interfaces for users' PCs and mobile information terminals, and administrators' PCs. Figure 3 shows the interface for users' PCs. The system enables users to accumulate and share their knowledge from experience and everyday life as residents, which can be considered "implicit knowledge", by changing it into explicit knowledge. Specifically, residents can help themselves strengthen their "ability to become aware" by submitting information on hazardous or safe locations that may not be listed in detail on hazard maps provided by the government during normal times, and submitting disaster information after securing one's safety during a disaster. Additionally, the government can improve its "ability to inform" by accumulating disaster information ("expert knowledge") such as the general degree of risk and support facilities during a disaster provided from normal times in advance in addition to gathering and accumulating disaster information provided during disasters. The disaster information provided through the submissions of residents and the 
government, as described above, are accumulated into the same database and categorized according to the location information and content. Furthermore, such disaster information is all integrated into the Web-GIS, combined and visualized on a digital map. Additionally, since the system was designed to be used both on PCs and mobile information terminals with the assumption that users will use the system outdoors as well, it can be used regardless of whether a user is inside or outside during both normal times and disasters.

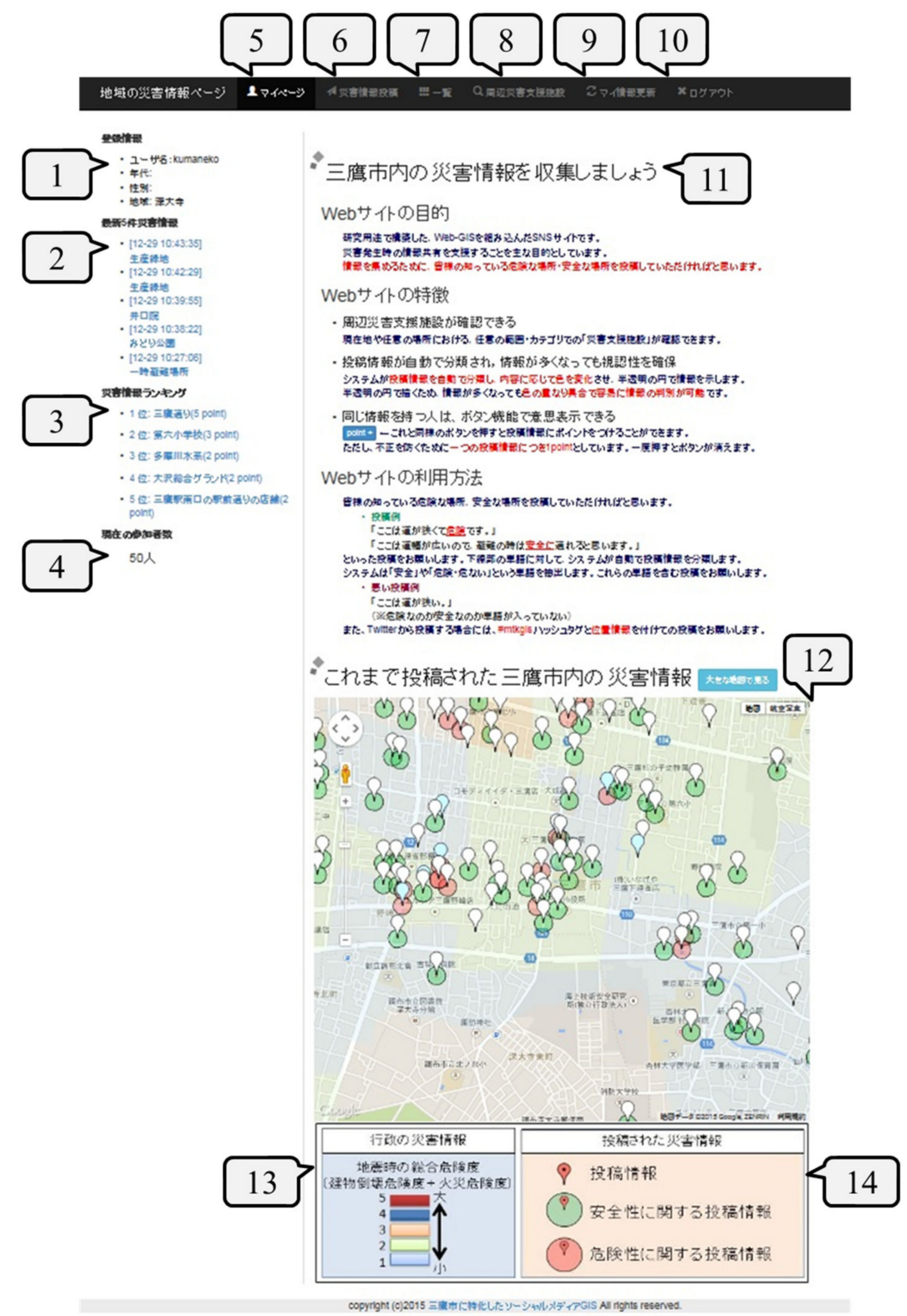

\begin{tabular}{|c|l|}
\hline No. & Description \\
\hline $\mathbf{1}$ & User profile publication \\
\hline $\mathbf{2}$ & The five most recent items of submitted information \\
\hline $\mathbf{3}$ & The five most important items of submitted information \\
\hline $\mathbf{4}$ & The number of users \\
\hline $\mathbf{5}$ & Go to my page \\
\hline $\mathbf{6}$ & Go to the page where information can be submitted from computers \\
\hline $\mathbf{7}$ & List of submitted information \\
\hline $\mathbf{8}$ & Go to the page where support facilities in times of disaster can be checked \\
\hline $\mathbf{9}$ & Go to the page where change and registration of personal data can be made \\
\hline $\mathbf{1 0}$ & Logout \\
\hline $\mathbf{1 1}$ & Explanation to use this system \\
\hline $\mathbf{1 2}$ & Disaster information is displayed on Web-GIS digital map in the region of operation (Mitaka City) \\
\hline $\mathbf{1 3}$ & General degree of risk \\
\hline $\mathbf{1 4}$ & Explanation of disaster information submitted by users \\
\hline
\end{tabular}

Figure 3. The interface of social media GIS for disaster information system for users' PCs. 
Figure 4 shows the distribution of submitted information to social media GIS on a digital map of Web-GIS. During the 2 months' operation test period from November to December in 2015, there were 260 submissions and 6 submissions from Twitter which were all sent from mobile information terminals. $81 \%$ of the total number of submissions had images attached, and $4 \%$ of those submissions received comments. As there was communication between users using the comment function, it can be anticipated that the function can also be used during disasters as well as normal times. Information regarding hazards was $20 \%$, information regarding safety was $68 \%$ and other information including disaster prevention storages, water stations and wells used during a disaster was $12 \%$. It can be presumed that users were not concentrated in one area, because the submitted information was dispersed throughout Mitaka City as shown in Figure 4. However, there were areas, especially around stations, with a slight concentration of submitted information. This may be because people come and go every day in such areas and the narrow streets become even narrower in some parts due to bicycles and luggage.

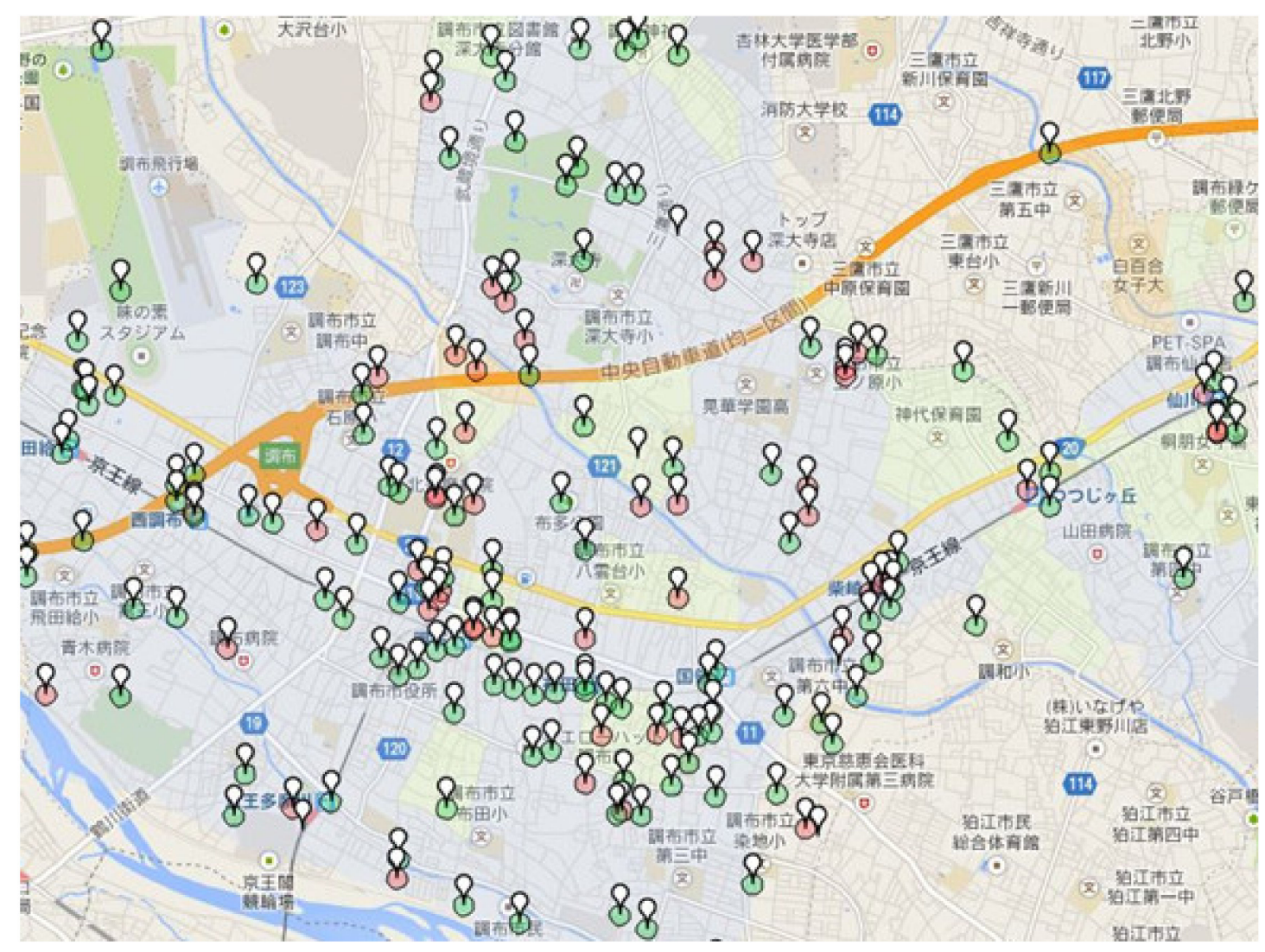

Figure 4. Distribution of information submitted to the social media GIS for disaster information system.

Figure 5 shows an example of submitted information with an attached image. This submission is for potential hazards, and it explains how a location may be hazardous during a disaster due to boxes and bicycles left on both sides of a narrow street. 


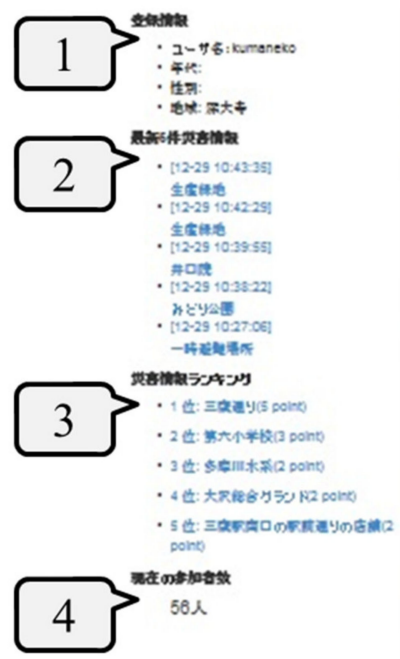

下連雀3丁目の店舗間の道路 (1point)

2014-11.14 18:23:4 Ex: $m=$

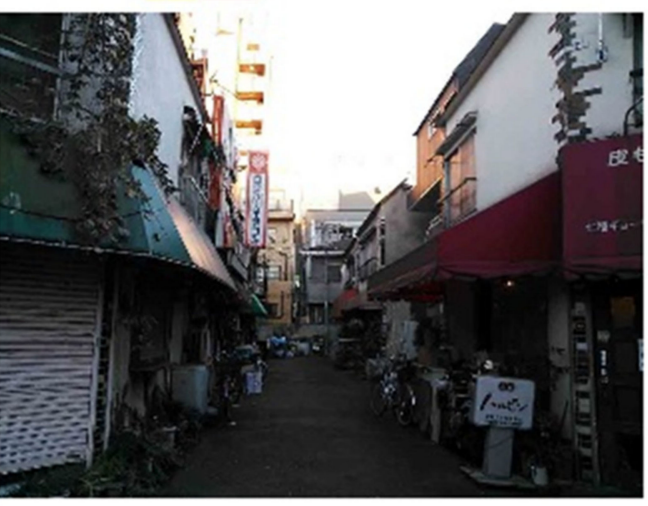

[内ํㅛㅇ]

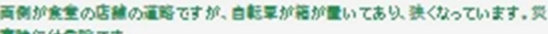

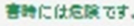
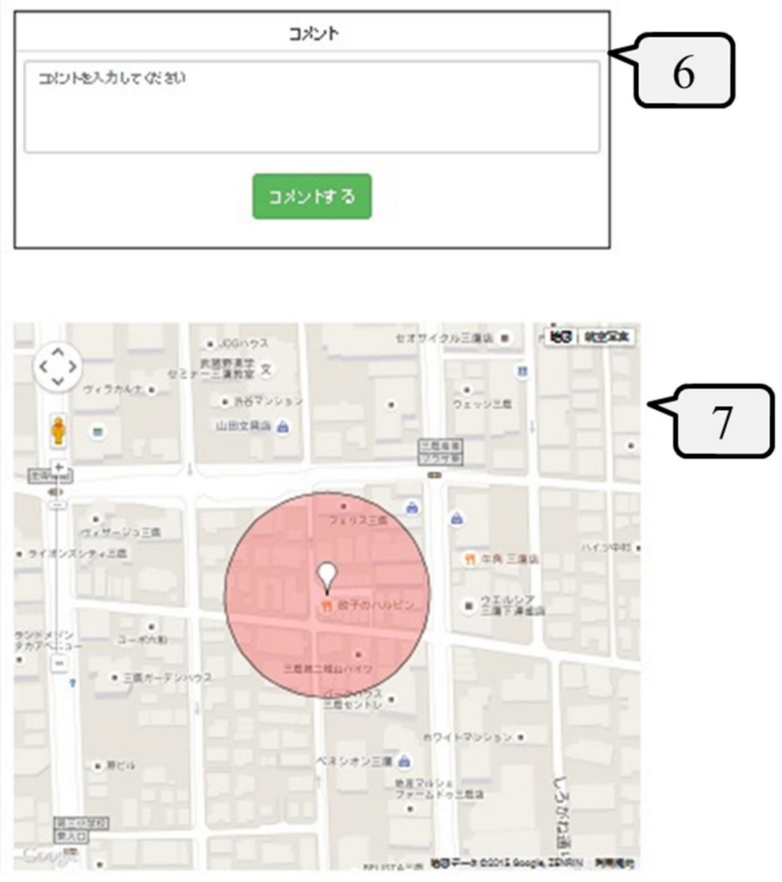

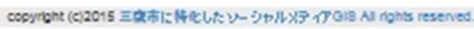

\begin{tabular}{|r|l|}
\hline No. & Description \\
\hline $\mathbf{1}$ & User profile publication \\
\hline $\mathbf{2}$ & The five most recent items of submitted information \\
\hline $\mathbf{3}$ & The five most important items of submitted information \\
\hline $\mathbf{4}$ & The number of users \\
\hline $\mathbf{5}$ & Submitted information and image \\
\hline $\mathbf{6}$ & Comment column \\
\hline $\mathbf{7}$ & Disaster information is displayed on Web-GIS digital map in the region of operation (Mitaka City) \\
\hline
\end{tabular}

Figure 5. An example of submitted information on the social media GIS for disaster information system. 


\section{Utilization Potential of Social Media Mapping as a Digital Infrastructure}

Makino et al. $(2018,2019)[8,9]$ integrated multiple systems including social media and Web-GIS to develop a spatiotemporal information system. The following will introduce case examples related to the function of social media mapping. The spatiotemporal information system is categorized into education and tourism depending on the intended use, and the function of social media mapping is part of the tourism system. By using the function, submitted information with location information from all over the world is gathered from 5 social media platforms (Instagram, Twitter, Flickr, YouTube and Webcams), and consolidated to be displayed on a two-dimensional digital map of Web-GIS. Though disaster countermeasures are not the original purpose of the system, much disaster-related information could be gathered during the heavy-rain disaster in Western Japan in 2018. Moreover, the heavy-rain disaster in Western Japan in 2018 was caused by Typhoon Prapiroon and heavy rainfall during the rainy season resulting in great damage in 15 prefectures in Western Japan.

Figure 6 shows a screen displaying the Setouchi Region using the function of social media mapping. The number of submissions during the heavy-rain disaster in Western Japan in 2018 rapidly increased, and Figure 6 reveals that this number was especially high in the worst-hit areas. Figure 7 shows the submitted information in Mabi-cho, Kurashiki City, Okayama Prefecture, Figures 8 and 9 respectively show those of Fukuyama City, Hiroshima Prefecture and Ozu City, Ehime Prefecture. As shown in Figure 7, Mabi-cho is on the outskirts of Kurashiki City and suffered enormous damage due to the floods leading to videos of the damage situation submitted on YouTube. There are many reservoirs distributed throughout Western Japan, and when one of these in Fukuyama City collapsed due to the heavy rain, a video of the situation was submitted on YouTube as shown in Figure 8. In central Ozu City, flood damages caused by the flooding of the Hijikawa River have frequently occurred in the past, and images of the damage situation from the heavy-rain disaster in Western Japan in 2018 were submitted on Instagram as shown in Figure 9.

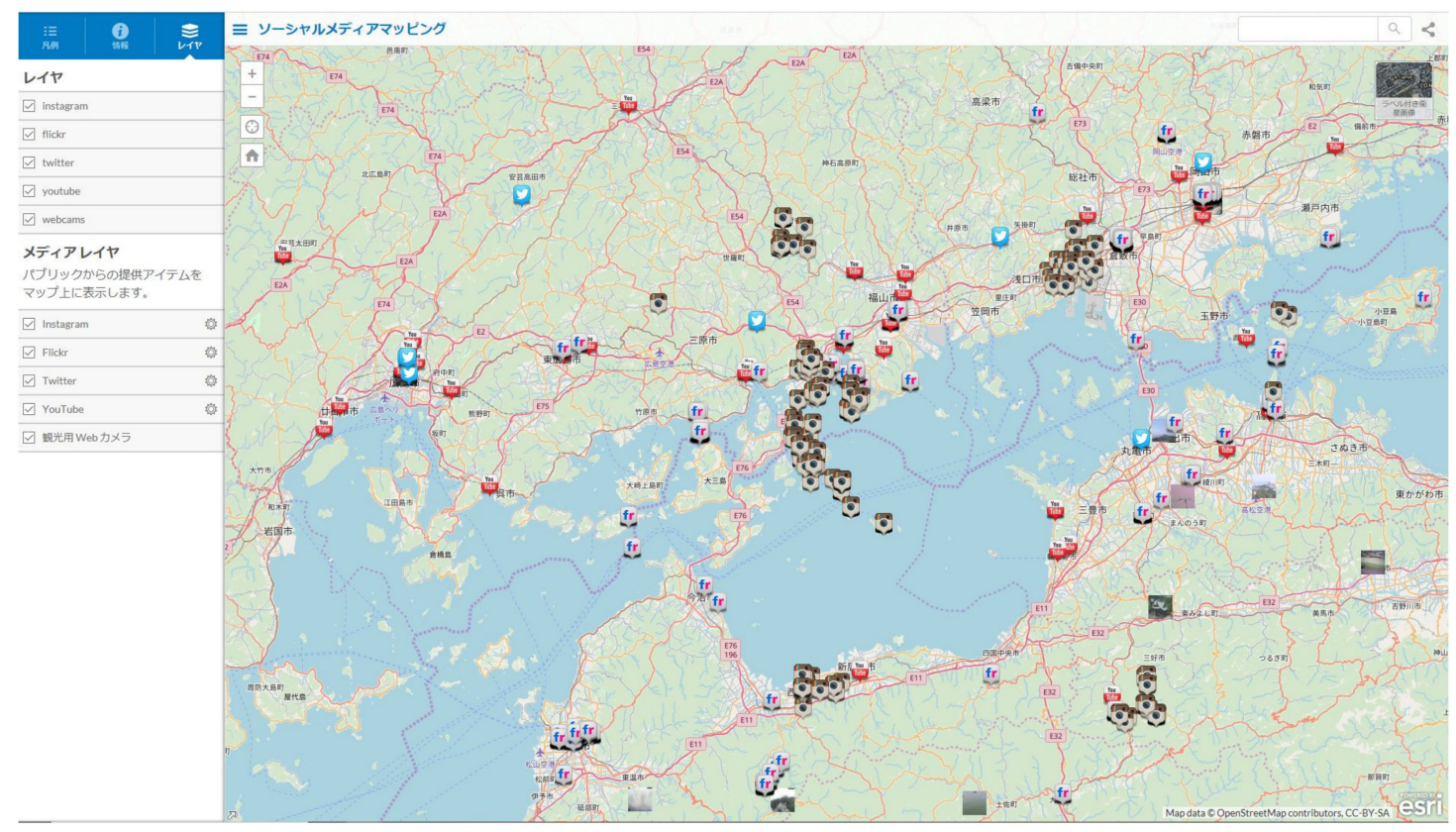

Figure 6. A screen of the Setouchi Region displayed using the function of social media mapping. 


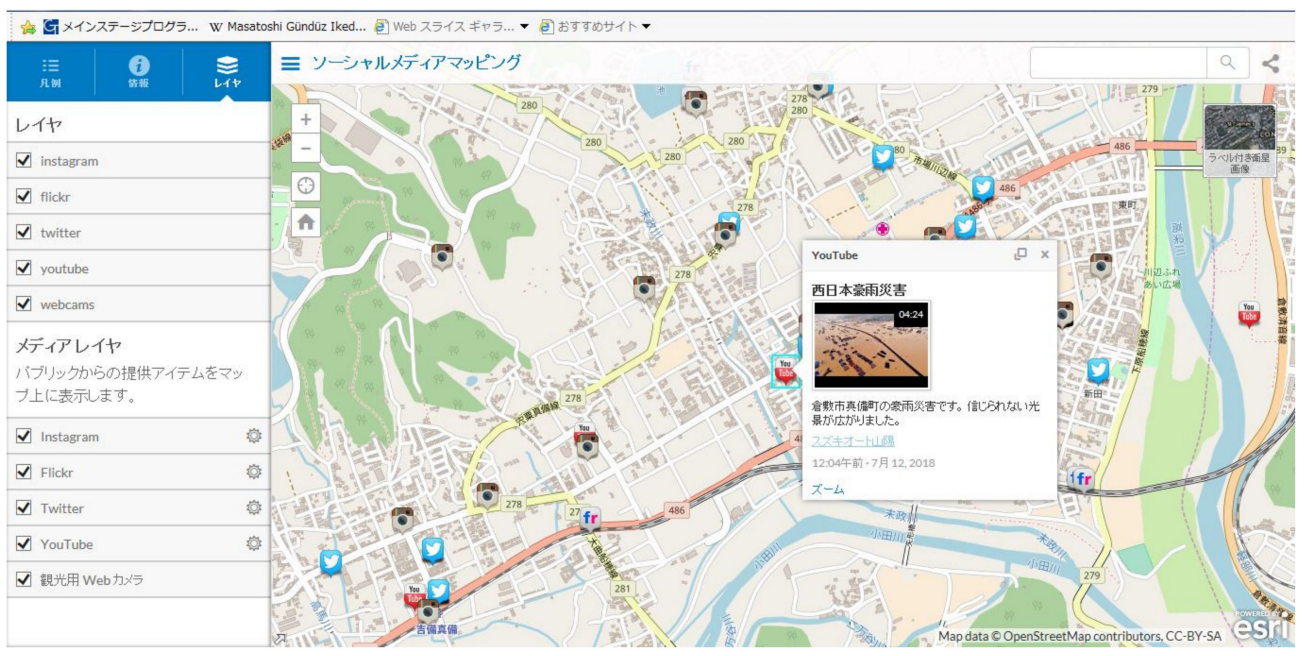

Figure 7. Submissions on YouTube concerning Mabi-cho, Kurashiki City, Okayama Prefecture.

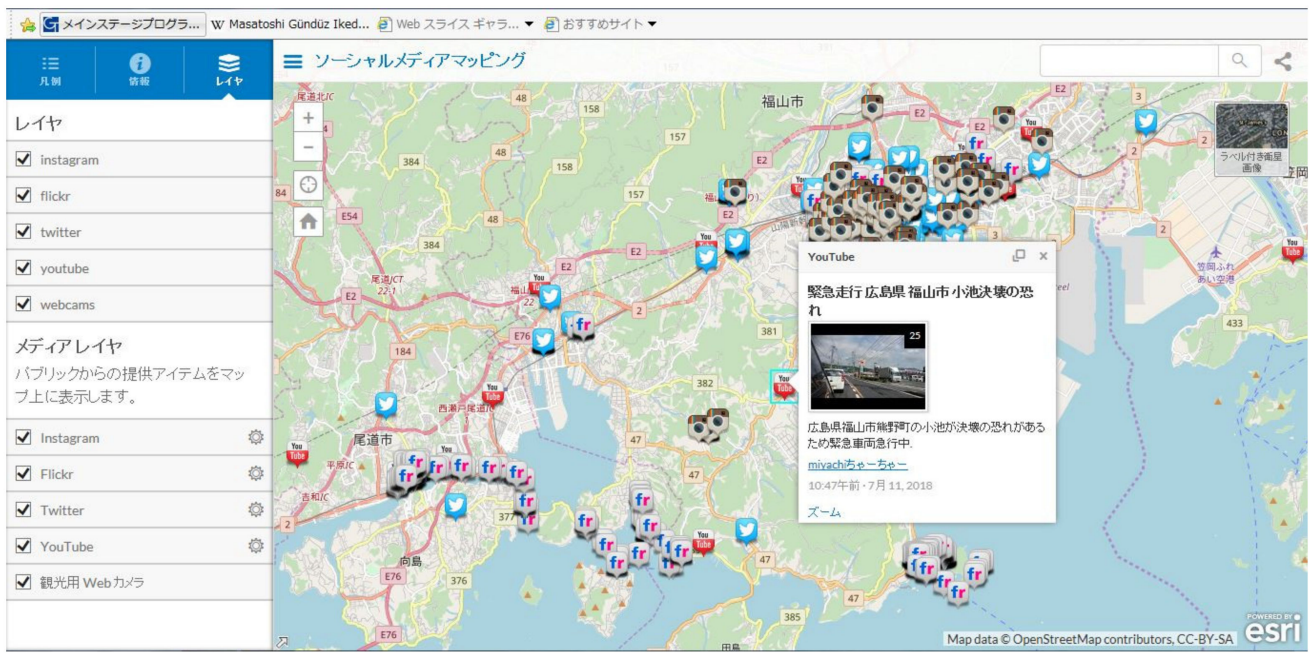

Figure 8. Submissions on YouTube concerning Fukuyama City, Hiroshima Prefecture.

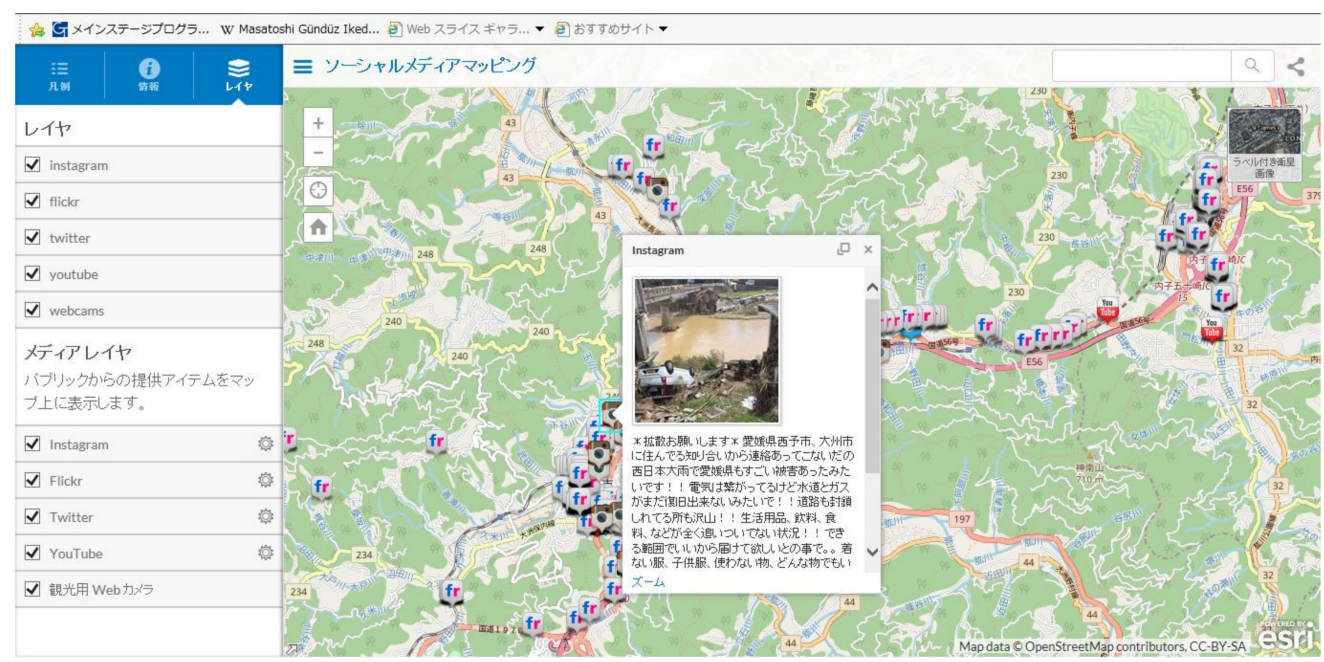

Figure 9. Submissions on Instagram concerning Ozu City, Ehime Prefecture.

It has become evident that disaster-related information can be efficiently gathered during disasters by not only consolidating the submissions with location information to the digital map but also by searching for submissions using the search function of each social media platform, with the function 
of social media mapping. Additionally, it was also found that the location information attached to submissions could become "life-saving information" during a disaster.

\section{Utilization Potential of Twitter as a Digital Infrastructure Based on the Cases of the Heavy-Rain Disaster in Western Japan in 2018}

\subsection{Utilization of Twitter during the Heavy-Rain Disaster in Western Japan in 2018}

As the situation during disaster constantly changes, Twitter, which is a platform where users can submit short texts, images and videos, was the most used platform in Japan and was used for various purposes. Additionally, referring to Nishikawa et al. (2018) [33] and Yamada et al. (2019a, 2019b) [34,35], Twitter was used as the most powerful tool for information communication during the heavy-rain disaster in Western Japan in 2018. Therefore, the present study focuses on the use of Twitter among social media.

Twitter, released in the U.S. in 2006 and in Japan in 2008, is a blog service in which users can submit what they are currently doing or feeling as well send short messages in the form of texts within 280 words (140 letters in Japanese) called "tweets". A big feature of Twitter is the hashtag function which serves as a symbol used to group tweets that can be searched and displayed. Hashtag is a word or phrase with the \# symbol in front, and users can see a list of tweets with the same hashtag like a bulletin board. Adding a hashtag makes it easier for others to see "what the tweet is about".

The used hashtags in tweets related to the heavy-rain disaster in Western Japan in 2018 can be organized as shown in Table 1 . Table 1 clearly indicates that the attached hashtags changed with the passing of time. In terms of the characteristics of hashtags, (1) multiple different hashtags indicating the same content were created, (2) almost all tweets had hashtags and many had multiple hashtags, (3) most tweets contained hashtags of specific local governments affected by the disaster in addition to hashtags related to the disaster situation and calls for help, and (4) there were many tweets with hashtags of specific areas within Mabi-cho, Kurashiki City, Okayama Prefecture, which suffered severe damages and was frequently covered by media. Additionally, there were many cases where users with good intentions voluntarily organized rescue request information and retweeted such information even without hashtags to be spread.

Table 1. Utilization of hashtags in tweets related to the heavy-rain disaster in Western Japan in 2018.

\begin{tabular}{|c|c|}
\hline \multicolumn{2}{|c|}{ Hashtags during and Immediately after the Disaster } \\
\hline Disaster situation & $\begin{array}{c}\text { \#disaster \#landslidedisaster \#landslides \#mudslides \#pouringrain } \\
\text { \#heavydownpour \#Hiroshimalandslides \#disasterinHiroshima } \\
\text { \#flooddamage \#riverflooding \#torrentialrain \#heavyrainfall } \\
\text { \#raindamage \#heavyraindisaster \#heavyraindamage \#flooding } \\
\text { \#heavyrain \#submergence \#onthevergeofsubmergence \#submergedcar } \\
\text { \#house }\end{array}$ \\
\hline Rescue requests and cooperation & $\begin{array}{c}\text { \#evacuation } \\
\text { \#(affectedlocalgovernment(prefecture/city/town))evacuation } \\
\text { \#evacuationcall \#evacuationorder \#emergencywarning } \\
\text { \#heavyrainfallwarning \#heavyrainfallemergencywarning } \\
\text { (Including tweets obviously on someone's behalf based on the context) } \\
\text { \#rescuerequests \#rescuerequestsforOkayama } \\
\text { \#rescuerequestsforHiroshima \#rescuerequestsforEhime } \\
\text { \#rescuerequestsforMabicho \#(disaster)rescue \#(disaster)relief \#SOS } \\
\text { \#Pleasehelp \#HELP \#Landslideshelp \#helplandslides \#helpheavyrain } \\
\text { \#missing(person) \#safetyunknown }\end{array}$ \\
\hline
\end{tabular}


Table 1. Cont.

\begin{tabular}{|c|c|}
\hline \multicolumn{2}{|c|}{ Hashtags during and Immediately after the Disaster } \\
\hline & $\begin{array}{c}\text { \#affectedareasoftheheavyraindisasterin westernjapanin2018 } \\
\text { \#(affectedlocalgovernment(prefecture/city/town)) }\end{array}$ \\
\hline Specific locations of the affected areas & \#Mabicho(KurashikiCity) \#(specific areas or rivers) \\
\hline & $\begin{array}{l}\text { \#(specificlocations(schools and other facilities that are designated as } \\
\text { evacuation centers and hospitals)) }\end{array}$ \\
\hline Name of the specific locations within Mabi-cho & $\begin{array}{l}\text { \#147ofTsujitaMabicho \#YataMabicho \#KawataMabicho \#OkadaMabicho } \\
\text { (Including tweets without hashtags but contain requests to be retweeted) }\end{array}$ \\
\hline Information communication & $\begin{array}{l}\text { \#pleaseretweet \#retweet \#RT \#PleaseRT \#warnings } \\
\text { \#currentsituationnotreported }\end{array}$ \\
\hline \multicolumn{2}{|c|}{ Hashtags from Immediately after the Disaster } \\
\hline \multirow{5}{*}{ Name of the disaster } & \#HeavyraindisasterJuly2018 \#HeavyrainJuly2018 \\
\hline & \#disasterfrom2018JapanFloods \#2018JapanFloods \\
\hline & \#WesternJapandisaster \#heavyrain2018 \\
\hline & \#(disaster)restoration \#(disaster)recovery \#medicalcare \#DMAT \\
\hline & $\begin{array}{l}\text { \#watersupply \#(disaster)volunteer \#volunteerswanted \#evacuationsite } \\
\text { \#(specificevacuationsite) \#(disaster)support \#reliefsupplies(specific }\end{array}$ \\
\hline \multirow[t]{3}{*}{ Support } & supplies) \\
\hline & \#wewillsendsupplies \#bath \#shower \#onsen\#disastervictims \\
\hline & $\begin{array}{l}\text { \#affectedareas \#Letthisreachthedisastervictims \#helpingeachother } \\
\text { \#SDF(dispatched) }\end{array}$ \\
\hline Encouragement & $\begin{array}{l}\text { \#StaystrongWestJapan \#Staystrong(affected local government } \\
\text { (city/town)) \#StaystrongMabicho \#Wecanbeattheheavyrain }\end{array}$ \\
\hline \multirow{2}{*}{ Donation and contributions } & \#2018JapanFloodsfund \\
\hline & \#2018JapanFloodsdisasterrestorationsupportfund \\
\hline \multirow[t]{2}{*}{ Designated disasters } & $\begin{array}{c}\text { \#tremendouscatastrophe \#designatedtremendous catastrophe } \\
\text { \#designatedspecifieddisaster }\end{array}$ \\
\hline & $\begin{array}{l}\text { \#wateroutage \#poweroutage \#heatstroke \#severeheat \#infections } \\
\text { \#sterilization \#traffic \#lackofmanpower \#lackofwater \#roadclosures }\end{array}$ \\
\hline \multirow[t]{2}{*}{ Post-disaster issues } & \#(disaster)theft \#trafficin(affected local government (city/town) \\
\hline & $\begin{array}{c}\text { \#donationfrauds \#chainemails \#falserumors \#Mabiheatstroke } \\
\text { \#Mabitraffic }\end{array}$ \\
\hline Gratitude & \#Iwasrescued \#gratitude \#thankyou \\
\hline Pets & \#pets(in affected areas) \#(pet food) \\
\hline
\end{tabular}

\subsection{Rescue Requests Using Twitter during the Disaster of the Heavy-Rain Disaster in Western Japan in 2018}

Regarding the heavy-rain disaster in Western Japan in 2018, the utilization of rescue request tweets was proposed by Twitter right after the disaster on July 10th. An example of a rescue request tweet was shown to clearly explain the items that must be included in the tweets. The examples indicated that users must enter specific rescue requests, their address, the hashtag "\#rescue", and (if possible) an attachment of images. Additionally, there was a cautionary note to immediately delete the tweet after being rescued. This was to prevent the tweets of those still waiting to be rescued from being buried among other tweets, and protect personal information such as an individual's address. Twitter has implemented similar support activities during other disasters such as the great East Japan earthquake in 2011 in addition to the Typhoon Krosa and Typhoon Hagibis in 2019.

A tweet related to the elderly person rescued by the Self-Defense Forces (SDF) was submitted during the heavy-rain disaster in Western Japan in 2018. This tweet contained appreciation to the SDF who were able to rescue the elderly person after her family members living away from the area submitted a rescue request tweet on her behalf. Many similar tweets were seen after the heavy-rain disaster in Western Japan in 2018.

\subsection{Utilization Potential of Twitter as a Familiar Digital Infrastructure Concerning Disaster Countermeasures}

Based on the utilization of Twitter in the heavy-rain disaster in Western Japan in 2018 described in this section, the following suggests the utilization potential of Twitter as a familiar digital infrastructure 
during disasters. However, consideration is required when setting rules for the utilization of Twitter during disasters as the freedom of utilization outside the affected area should not be restricted.

First, the format of the texts for tweets can be created according to its purpose of transmitting information such as evacuation, rescue request and cooperation, support, donation and contribution. In the disasters in recent years, Twitter has encouraged users to use the hashtag "\#rescue", and instructed them on the specific content of rescue requests leading to some tweets aiding in successful rescues. Accordingly, if text formats for tweets according to the purpose are prepared beforehand, the convenience of information senders, rescuers, and supporters will be improved.

Second, the unification of disaster-related hashtags can be raised. There is a possibility of confusion caused by information overload, as multiple types of hashtags indicating the same content are created during a disaster. Therefore, in the early stages of a disaster, the generation of various hashtags can be prevented by preparing unified hashtags and its utilization method that can be easily used by the general public. The background for this is the information gathering and rescue activities using Twitter in Nagano Prefecture during Typhoon Hagibis in October 2019. Nagano Prefecture used their official account for disaster prevention information as a tool to gather rescue request information, and encouraged users that need be rescued to submit tweets with images, location information, and the hashtag "\#TyphoonHagibisDamageinNagano" resulting in 50 cases of tweets leading to successful rescues (Yamamoto, 2020) [36]. Based on these real cases during disasters, each local government can promote the setting of rules for utilizing Twitter according to the local situation beforehand.

Lastly, the improvement of information literacy for each individual user can be raised. It is ideal to have users refrain from submitting personal tweets (opinions, thoughts, and vague personal comments) as well as tweets that may not be reliable or valid, and voluntarily delete old tweets related to disasters as the situation is constantly changing. Especially for tweets related to rescue requests and cooperation, it is essential to delete the tweet right after the situation is resolved. This will prevent the tweets of those still waiting to be rescued from being buried among other tweets as well as protect personal information such as an individual's address. Additionally, users must give serious thought to the information they are retweeting with the awareness that retweets made with good intentions may also cause confusion due to information overload. In this regard, Sato et al. (2019) [37] pointed out the difficulty in searching for and extracting the important tweets related to rescue requests and cooperation during the heavy-rain disasters in North Kyusyu in 2017 and in Western Japan in 2018.

\section{Conclusions}

The present study focused on social media and GIS of ICT as a digital infrastructure, which play important roles in disaster countermeasures. The present study also introduced development cases of the system developed integrating these, and presented the utilization potential as a digital infrastructure. Additionally, Twitter, which is the most-used social media platform for disaster countermeasures in Japan, was focused on, and its utilization cases during the heavy-rain disaster in Western Japan in 2018 were considered as well as the utilization potential of Twitter as a familiar digital infrastructure in disaster countermeasures was indicated.

As mentioned in Section 3.1, as the reality and virtual spaces are closely related and integrated in super-smart societies such as Japan, everyday events in either space influences the other space. Therefore, if a disaster in reality occurs, the transmission and reception of disaster-related information in the virtual space using various information communication methods such as mass media and social media start almost simultaneously. As explained in Section 7.2, while this can lead to real activities such as evacuation, relief and support, it can also cause problems such as confusion due to information overload. Therefore, the issue is how to make the information circulating in the virtual space and especially on social media efficiently and effectively aid in the rescue and support activities in the reality space.

In order to solve such an issue, as mentioned in Section 7.3, it is necessary to not only set rules for the utilization of social media but also to sift through information and share only the necessary 
information to the affected local governments and those involved in the rescue and support activities. In doing this, if the social media GIS for disaster information system and the function of social media mapping of the spatiotemporal information system which were introduced in Sections 5 and 6 are utilized, the essential information can be efficiently consolidated on the digital map of Web-GIS. Additionally, while Section 7 indicated the utilization potential of Twitter alone during disasters, the same utilization potential of other social media platforms based on their characteristics should be considered.

Furthermore, various information communication methods including verbal calls in addition to ICT are necessary in order to prevent people who are vulnerable to disasters from becoming people who are also vulnerable to information. Though prompt evacuation may not be realized, due to the normalcy bias where an individual has the "I'm okay" mentality during disasters, finding a way to effectively use ICT to encourage individuals to evacuate is an issue. It is necessary for individuals who are not used to using ICT to familiarize themselves with utilizing it in their daily life.

Regarding future research projects, increasing the utilization performance of the systems as introduced in Sections 5 and 6 as well as investigating the utilization potential of various social media platforms using the same methods adopted in Section 7 can be raised.

Funding: This research received no external funding.

Conflicts of Interest: The author declares no conflict of interest.

\section{References}

1. Cabinet Office. White Paper on Disaster Management 2018; Cabinet Office: Tokyo, Japan, 2018; 237p.

2. Yamamoto, K. Utilization possibility of a disaster information system in cooperation with local communities. Governance 2016, 212, 23-25.

3. Cabinet Office. 5th Science and Technology Basic Plan; Cabinet Office: Tokyo, Japan, 2016; 59p.

4. Science Council of Japan. Recommendations: Towards the Accumulation and Utilization of "Local Knowledge"; Science Council of Japan: Tokyo, Japan, 2008; 25p.

5. Yanagisawa, T.; Yamamoto, K. Study on information sharing GIS to accumulate local knowledge in local communities. Theory Appl. GIS 2012, 20, 61-70. [CrossRef]

6. Okuma, T.; Yamamoto, K. Study on a social media GIS to accumulate urban disaster information: Accumulation of disaster information during normal times for disaster reduction measures. Socio-Informatics 2013, 2, 49-65.

7. Yamamoto, K.; Fujita, S. Development of social media GIS to support information utilization from normal times to disaster outbreak times. Int. J. Adv. Comput. Sci. Appl. 2015, 6, 1-14. [CrossRef]

8. Makino, R.; Yamamoto, K. Spatiotemporal information system for use in geography education. Theory Appl. GIS 2018, 26, 53-63.

9. Makino, R.; Yamamoto, K. Spatiotemporal information system using mixed reality for area-based learning and sightseeing. In Lecture Notes in Geoinformation and Cartography: Computational Urban Planning and Management for Smart Cities; Geertman, S., Allan, A., Pettit, C., Stillwell, J., Eds.; Springer: Cham, Switzerland, 2019; pp. 283-302.

10. Molina, M.; Bayarri, S. A multinational SDI-based system to facilitate disaster risk management in the Andean Community. Comput. Geosci. 2011, 37, 1501-1510. [CrossRef]

11. Wan, Z.; Hong, Y.; Khan, S.; Yong, B.; Flamig, Z.L.; Kirschbaum, D.; Tang, G. A cloud-based global flood disaster community cyber-infrastructure: Development and demonstration. Environ. Model. Softw. 2014, 58, 86-94. [CrossRef]

12. Ogata, A.; Manaka, A.; Sakurai, K.; Tsutsumi, M.; Suzaki, A.; Abe, R.; Uchida, O.; Ishii, H.; Utsu, K. Construction of a twitter-based safety confirmation system at the time of disaster and its development to be available when communication infrastructure is disrupted. IEICE Tech. Rep. 2016, 116, 29-34. 
13. Bhattacharjee, S.; Roy, S.; Das Bit, S. Post-disaster map builder: Crowdsensed digital pedestrian map construction of the disaster affected areas through smartphone based DTN. Comput. Commun. 2019, 134, 96-113. [CrossRef]

14. Cao, S.; Yamamoto, K. Seismic intensity area rapid assessment methods based on mobile phone base station data. In Proceedings of the 2019 Annual Meeting of the Society of Socio-Informatics, Tokyo, Japan, 13-15 September 2019; pp. 120-123.

15. Inomo, H.; Shiraki, W.; Imai, Y.; Isouchi, C.; Takemoto, M.; Yokoi, T. A consideration about the information gathering and transfer in a large-scale wide area disaster such as the eastern Japan great earthquake. J. Jpn. Soc. Civ. Eng. Ser. F6 (Saf. Probl.) 2012, 68, I-88-I-95.

16. Harada, H.; Ishizu, K.; Murakami, H. Effective use of cognitive wireless router in emergency situation of network infrastructure. J. Inst. Electron. Inf. Commun. Eng. 2012, 95, 207-212.

17. Hamaguchi, K.; Inoue, M.; Owada, Y.; Jeong, B. R\&D approach to disaster-resilient wireless telecommunication system. IEICE Tech. Rep. MoNA Mob. Netw. Appl. 2014, 114, 67-73.

18. Yoshimura, N.; Inoue, T. The use of Twitter around governmental accounts in and after the Great East Japan Earthquake. IPSJ SIG Tech. Rep. 2012, 2012-GN-83, 1-8.

19. Enomoto, H.; Uchida, O.; Toriumu, F. Extraction of effective feature for false rumor detection by analysis of tweets at the time of great east japan earthquake. In Proceedings of the Forum on Information Technology, Tottori, Japan, 4 September 2013; Volume 12, pp. 649-650.

20. Yamada, S.; Utsu, K.; Uchida, O. Feature analysis of tweets at the times of large-scale natural disasters. In Proceedings of the 2019 Annual Meeting of Japanese Society of Computational Statistics, Sendai, Japan, 1-2 June 2019; Volume 33, pp. 81-84.

21. Nakano, A.; Nakano, S.; Matsumoto, H.; Nakane, D.; Yamamoto, W.; Tsukai, M. Reactions of local government and of inhabitants to torrential rain disaster in Hiroshima prefecture. J. Jap. Soc. Civ. Eng. Ser. B1 (Hydraul. Eng.) 2019, 75, 414-428.

22. Alazawi, Z.; Alani, O.Y.K.; Abdljabar, M.B.; Altowaijri, S.; Mehmood, R. A smart disaster management system for future cities. In Proceedings of the 2014 ACM International Workshop on Wireless and Mobile Technologies for Smart Cities, Philadelphia, PA, USA, 11-14 August 2014; pp. 1-10.

23. Freeman, J.; Hancock, L. Energy and communication infrastructure for disaster resilience in rural and regional Australia. Reg. Stud. 2017, 51, 933-944. [CrossRef]

24. Fan, C.; Zhang, C.; Yahja, A.; Mostafavi, A. Disaster city digital twin: A vision for integrating artificial and human intelligence for disaster management. Int. J. Inf. Manag. 2019. [CrossRef]

25. Ministry of Internal Affairs and Communications. White Paper on Information and Communications 2002; Ministry of Internal Affairs and Communications: Tokyo, Japan, 2002; 367p.

26. Ministry of Education Culture, Sports, Science and Technology. White Paper on Science and Technology 2016; Ministry of Education Culture, Sports, Science and Technology: Tokyo, Japan, 2016; 339p.

27. Cabinet Office. Consumer Behavior Forecasting Survey 2014; Cabinet Office: Tokyo, Japan, 2014; 12p.

28. Ministry of Internal Affairs and Communications. White Paper on Information and Communications 2016; Ministry of Internal Affairs and Communications: Tokyo, Japan, 2016; 437p.

29. Yamamoto, K. Utilization of information infrastructure supporting urban activities for disaster reduction and management. Road Constr. 2017, 762, 29-33.

30. Central Disaster Prevention Council. Committee for Policy Planning on Disaster Management Final Report-Toward the Reconstruction for Sound and Unwavering Japan; Central Disaster Prevention Council: Tokyo, Japan, 2012; 48p.

31. Cabinet Office. Master Plan for Disaster Prevention; Cabinet Office: Tokyo, Japan, 2016; 633p.

32. Yamamoto, K. Development and future prospects for information systems in environmental science and disaster management. Environ. Sci. 2015, 28, 73-84.

33. Nishikawa, S.; Tanaka, N.; Ohdaka, R.; Sato, H.; Kondo, M.; Uchida, M.; Utsu, K. Analysis of rescue request tweets in the July 2018 heavy rain disaster in Japan. IEICE Tech. Rep. 2018, 118, 43-48.

34. Yamada, S.; Utsu, K.; Uchida, M.; Cho, K. Analysis of tweets posted during 2018 Typhoon Jebi disaster. IEICE Tech. Rep. 2019, 118, 63-68.

35. Yamada, S.; Utsu, K.; Uchida, M.; Cho, K. Analysis and visualization of attention area of tweets during disasters. IEICE Tech. Rep. 2019, 119, 1-6. 
36. Yamamoto, K. Utilization of ICT for disaster countermeasures. Creat. Boso 2020, 99, 3-8.

37. Sato, S.; Imamura, F. An analysis of tweet data tagged with "\# Rescue" in the 2018 West Japan Heavy Rain Disaster: Comparative analysis with the case of 2017 North Kyushu Heavy Rain Disaster. J. Nat. Disaster Sci. 2019, 37, 383-396. 